\title{
Nota: \\ Um Regime sob Consultas
}

Sergio Buarque de Hollanda Filho
Professor do Departamento de

Economia da FEA-USP

\section{RESUMO}

Meu objetivo central, neste artigo, é discutir a interação entre as medidas de política industrial dirigidas ao setor automotivo brasileiro a partir do regime elaborado em 1995 e as controvérsias sobre as mesmas no âmbito da OMC. No caso examinado, o questionamento não passou da fase de consultas. Sendo o setor montador constituído por grandes empresas multinacionais, as medidas foram sendo adaptadas de forma a satisfazer reivindicações comerciais levantadas pelos membros da OMC que, potencialmente, teriam seus interesses afetados.

\section{PALAVRAS-CHAVE}

Brasil e OMC, regime automotivo brasileiro, regime automotivo do Mercosul, OMC e política industrial

ABSTRACT

I discuss, in this paper, the interaction between the policies for the Brazilian automotive sector in the second half of the nineties and the disputes in the WTO. The questioning was limited to the consultations phase. Since the sector is constituted by multinationals corporations, the rules of the regime were adapted in order to satisfy the demands of those WTO members whose interests might have been affected by the policy measures.

KEY WORDS

Brazil and WTO, Brazilian automotive regime, Mercosur automotive regime, WTO and industrial policy

JEL Classification

$\mathrm{FI3}$ 
Discuti, em artigo anterior (HOLLANDA, 2003), os aspectos dos acordos atingidos na Rodada Uruguai do GATT que iriam direcionar as diversas consultas realizadas no âmbito da Organização Mundial do Comércio (OMC) sobre as medidas de política industrial para o setor automotivo adotadas pelo governo brasileiro a partir do regime promulgado em dezembro de 1995. Resumi, então, os principais aspectos da versão original deste regime.

No presente artigo serão discutidas as diversas medidas adicionais introduzidas nessa política setorial, de forma correlata com as consultas, sobre o assunto, que se realizavam na OMC. Como será visto, os acordos administrados pela nova instituição não irão impor um limite inflexível no alcance das medidas de política industrial e comercial; contudo, implicarão novos padrões para as negociações sobre essas políticas que irão ocorrer em consultas bi ou multilaterais, sempre sob a ameaça da questão ser levada a um panel no Órgão de Soluções de Controvérsias da OMC. De forma correlata, também será analisado o caminho, com diversos entraves, para o estabelecimento de um regime comum no âmbito do Mercosul.

\section{A CARONA NO REGIME ARGENTINO}

O regime automotivo brasileiro continha inúmeros aspectos semelhantes ao argentino, desde vantagens para importações (inclusive de veículos) para as montadoras instaladas no País até o recurso a medidas de investimento relacionadas ao comércio (TRIMs). Representantes dos países do Mercosul, ou somente aqueles de seus dois principais membros, mantiveram reuniões para discussão sobre um acordo para o setor desde junho até dezembro de 1995. ${ }^{1}$ Ficava explícito, nessas reuniões, a intenção do governo brasileiro em pegar "carona" no regime argentino para abrir espaço para aprovação do regime brasileiro na OMC. O objetivo dessas reuniões ainda não era o de editar regras para um regime comum, mas sim o de procurar compatibilizar as regras dos dois regimes, deixando-se expresso a previsão para um futuro

1 Os acordos sobre o setor automotivo no Mercosul eram, tipicamente, precedidos por reuniões bilaterais entre os dois principais membros, nas quais negociavam-se regras que seriam, posteriormente, adaptadas para os outros dois membros. 
regime comum. O fato de a Argentina e o Uruguai terem notificado seus regimes automotivos (com as respectivas TRIMs) por ocasião da fundação da OMC, enquanto no Brasil o novo regime ainda não fora estabelecido - e nenhuma TRIM fora notificada ${ }^{2}$ - garantia, a nossos parceiros, uma posição mais cômoda no âmbito do organismo internacional. Isso porque o acordo na OMC vedava a imposição de novas TRIMs durante o período de transição para eliminação daquelas já vigentes e notificadas. As TRIMs que seriam oficializadas com o novo regime estariam, em princípio, contrariando o compromisso assumido pelo País. Uma vez adotadas, a Argentina perderia as vantagens que tinha em relação ao Brasil com respeito à atração para novos investimentos externos. Mas nosso parceiro não tinha condições de criar dificuldades para essa política brasileira; o maior tamanho de nosso mercado constituía um forte motivo para que evitassem a criação de dificuldades para a consolidação do mercado regional.

Em 22/1/96, menos de um mês após a assinatura do decreto que estabelecia o regime brasileiro, os dois países assinaram um novo acordo bilateral para o setor automotivo, que revia o anterior assinado em Ouro Preto. ${ }^{3}$ O novo acordo mantinha a meta de um regime comum para o ano 2000 - para quando se previa um completo livre comércio entre os dois países no setor automotivo - e estabelecia as regras para o período de transição que estava previsto para durar até o final de 1999. Ficava estabelecido o livre comércio (alíquota nula) para importações de uma montadora que fossem compensadas por exportações para qualquer destino; fora do comércio compensado, admitia-se a aplicação de regras específicas não fixadas pelo acordo. Regras foram também estabelecidas para o setor de autopeças, e

2 Na época da conclusão da Rodada Uruguai, um requisito de conteúdo nacional era vigente para o caso específico do carro popular. Observe-se, também, que as importações que receberam incentivos dos últimos contratos do Programa BEFIEX, assinados na segunda metade da década anterior, envolviam compromissos de exportação que se estenderiam até o final dos anos noventa.

3 Na Reunião de Ouro Preto, em dezembro de 1994, o Brasil, ao contrário da Argentina, não colocara o setor automotivo em sua lista de exceções aos princípios gerais da união alfandegária: eliminação da tarifa de importação e tarifa externa comum (TEC) (ver HOLLANDA, 1996). Com o aumento das tarifas, o compromisso brasileiro seria rompido; em maio de 1995, o Brasil oficializa a inclusão do setor automotivo em sua lista. 
índices de nacionalização seriam fixados, em cada país, por sua respectiva legislação nacional. Regras especiais ainda deveriam ser elaboradas para as montadoras que só operavam em um país.

\section{EMPECILHOS AO NOVO REGIME NA OMC}

O governo brasileiro já estava, evidentemente, consciente dos problemas que iria enfrentar com o novo regime na $\mathrm{OMC}$, mesmo antes da publicação do decreto. As manifestações contrárias às TRIMs, introduzidas pela MP 1024, haviam evidenciado este ponto. Na data da publicação do decreto que criava o novo regime, o então ministro das Relações Exteriores, Celso Lafer fornecia, a um órgão da imprensa (Gazeta Mercantil, 28/12/1995), entrevista na qual adiantava elementos de sua próxima argüição em defesa do novo regime, especificamente sobre as TRIMs nele contido. Ela se basearia na tese da necessidade de harmonização das regras internas ao Mercosul, de maneira a evitar distorções nas condições de concorrência entre seus membros. As referências a regras dos acordos da OMC então citadas para a defesa do regime estavam contidas nos dispositivos do Artigo 5:5 do Acordo TRIMs e o Artigo 16:4 do Acordo sobre Subsídios e Medidas Compensatórias (SMC).

O Artigo 5:5 dispõe sobre exceção à regra que proíbe a adoção de novas TRIMs inconsistentes com os artigos III (tratamento nacional) e XI (eliminação geral das restrições quantitativas) do GATT-94. A exceção visa não "prejudicar" firmas já estabelecidas que estivessem sujeitas a TRIMs durante o período de transição; para tal, admitia-se que um membro da OMC aplicasse as mesmas medidas a um novo investimento durante o período, seja no caso em que seus produtos fossem "similares àqueles de empresa estabelecida", seja em "caso necessário para evitar distorções nas condições de concorrência entre o novo investimento e as empresas já estabelecidas." O dispositivo não faz referência a empresas (estabelecidas ou novas) localizadas em países diferentes que constituam um bloco regional, donde a tentativa de usá-lo com o complemento do Artigo 16 do Acordo SMC, que trata da definição da "indústria nacional” para as finalidades deste acordo. Seu parágrafo 4 estabelece que "quando dois ou mais paises tiverem atingido tal nivel de integração previsto no 
dispositivo" do Artigo XXIV:8(a) do GATT (que trata da definição de união aduaneira), "que adquiram caracteristicas de mercado ínico, a indústria contida na totalidade da área integrada será considerada como indústria nacional..." para as finalidades do acordo.

Tentava-se, portanto, utilizar dispositivos do Acordo SMC para que o setor automotivo das duas nações fosse considerado, em conjunto, uma única indústria integrada, em razão das semelhanças entre os dois regimes rumo a uma integração em um único regime. Daí procurar-se-ia justificar a aplicação de TRIMs no Brasil fora do prazo previsto em virtude da notificação da medida pela Argentina (no prazo previsto) e da regra de exceção do acordo. Ao pé da letra dos dispositivos dos acordos, a aceitação da argumentação brasileira seria problemática, numa época em que já não havia boa vontade em relação às regras de tratamento especial e diferenciado. Por outro lado, não há como negar que a aplicação das TRIMs em apenas um país (ou em dois, com o Uruguai) provocaria "distorçôes nas condições de concorrência”, notadamente no que diz respeito à atração para novos investimentos, que traria vantagens para a indústria argentina. Caso o Brasil fornecesse incentivos à importação não vinculados ao equilíbrio na balança comercial, problemas poderiam se intensificar na balança comercial.

Em resumo, mesmo que pudessem ser colocadas restrições sobre a pertinência da aplicação do dispositivo do Artigo 16:4 do Acordo SMC, ou seja, mesmo que não se aceitasse a identidade do conjunto das duas indústrias como uma única indústria nacional - ou que não se aceitasse o dispositivo daquele artigo para aplicação em outro acordo -, não se poderia negar que, dentro do processo de integração em andamento, um benefício auferido apenas por uma das partes seria suficiente para provocar distorções nas condições de concorrência - argumento que dá sustento à exceção prevista no Artigo 5:5 do Acordo TRIMS.

Lafer ainda cita, na mesma entrevista, um outro argumento, relacionado ao dispositivo do Tratado de Assunção que estabelece uma coordenação de políticas setoriais entre membros do Mercosul, como o que acabava de se concretizar com a criação do novo regime brasileiro, com regras semelhantes às adotadas na Argentina. 
A primeira comunicação de Lafer sobre o regime automotivo na OMC foi apresentada no final de janeiro de 1996, em reunião do Conselho sobre Comércio de Bens. O representante brasileiro comunica a intenção do País solicitar um pedido de derrogação (waiver) de suas obrigações na OMC (conforme dispositivos do Artigo IX do GATT). A solicitação para a aceitação de medidas do regime (índice de nacionalização e compensação comercial) que contrariariam regras de acordos da OMC se basearia na necessidade de adaptar o regime brasileiro ao de seu parceiro. Mas, no mesmo dia, representantes de dois membros (Japão e Coréia do Sul) manifestam-se informalmente contrários ao pedido brasileiro. A oposição dos dois países asiáticos ao novo regime era de se esperar, uma vez que estes eram, entre os principais membros produtores de automóveis, aqueles que não tinham montadoras estabelecidas no País com atividade exportadora e nem tinham, até aquela data, manifestado intenção de se estabelecer no Brasil e/ou aderir ao regime.

O pedido de derrogação em relação às provisões do Acordo TRIMs é solicitado em março de 1996. (WTO, 1996a). Diante da constatação de que o pedido não seria aprovado pela maioria de três quartos dos membros (conforme Artigo IX:3 do Acordo Constitutivo da OMC), o Brasil decide retirar o pedido em maio.

\section{AS PRIMEIRAS CONSULTAS SOBRE O NOVO REGIME}

O sistema de solução de controvérsia da OMC adota, como regra geral de comportamento, uma preferência por "solução mutuamente aceitável para as partes em controvérsia e que esteja em conformidade com os acordos abrangidos" (Artigo 3:7 do "Entendimento Relativo às Normas e Procedimentos sobre Solução de Controvérsias” (ESC)). E é sob esse prisma, de preferência por uma solução conciliatória em relação a um litígio, que existe a obrigação de consulta antes que qualquer conflito possa exigir o estabelecimento de um panel pelo Órgão de Solução de Controvérsias (OSC) da OMC (sobre o assunto, ver LAFER, 1998, p. 112-114).

O primeiro pedido formal de consultas sobre o regime brasileiro é feito pelo Japão em 30/7/96, tendo sido comunicado aos demais membros da 
OMC em 6/8/96. (WT/DS51/1). Sob a alegação de substanciais interesses afetados pelas medidas do governo brasileiro, conforme as prescrições do Artigo 4:11 do ESC, Coréia do Sul, União Européia, Estados Unidos e Canadá entram com pedidos de participação na consulta dentro do prazo de dez dias, o que a tornava multilateral ao invés de bilateral. ${ }^{4}$

As medidas estabelecidas pela MP 1235, pelo Decreto 1761 e pelas MPs seguintes sobre o regime automotivo constituem o alvo apontado nesses pedidos, os quais se referem, de maneira mais específica, aos requisitos de conteúdo nacional e de determinadas proporções entre valor das exportações e valor das importações (compensação comercial).

No pedido formalizado pelo Japão, as medidas tomadas pelo Brasil são consideradas inconsistentes com as obrigações assumidas na OMC, particularmente (mas não exclusivamente) com os dispositivos dos seguintes acordos: TRIMs - Artigo 2 (proibição de medidas incompatíveis com as disposições dos Artigos III e XI do GATT/94); GATT/94 - Artigos I:1 (nação-maisfavorecida), III:4 (tratamento nacional) e XI:1 (restrições quantitativas); SMC - Artigos 3 (proibição de subsídios vinculados ao desempenho exportador e ao uso preferencial de produtos nacionais), 27:2 (tratamento especial e diferenciado para subsídios vinculados ao desempenho exportador; a exceção seria consentida por oito anos, desde que obedecida a disposição do 27:4), e 27:4 (prevê uma eliminação preferivelmente progressiva dos subsídios tratados em 27:2 e estabelece condições para atendimento de eventual pedido de extensão do prazo). ${ }^{5} \mathrm{O}$ Japão faz, adicionalmente,

4 Esses pedidos são heterogêneos em termos de detalhamento. O da União Européia (UE) é o mais detalhado, com especificação dos produtos (a quatro dígitos na classificação padronizada) exportados que estariam sendo prejudicados pelas medidas do governo brasileiro e de dados sobre o valor dessas exportações em 1995. Por simplificação, manteremos a denominação União Européia mesmo no caso de referências a Comunidades Européias (CE). É a CE que representa os países da UE na OMC (e no Órgão de Solução de Controvérsias); mas é sobre a UE que é feito o exame do Órgão de Revisão de Política Comercial.

5 A mesma medida do Decreto 1761 que estabelece uma relação entre exportação e importação incentivada estava, aparentemente, sendo questionada tanto em razão do dispositivo sobre compensação comercial do Acordo TRIMs como daquele sobre desempenho exportador do Acordo SMC. Deve-se ter em mente que tanto na literatura especializada como nos processos que ocorrem no Órgão de Solução de Controvérsias é comum não se fazer distinção entre as medidas de compensação comercial e de desempenho exportador. O requisito de conteúdo nacional não é questionado por dispositivo do Acordo SMC, pois, neste, a exceção aberta para países em desenvolvimento (Artigo 27:3) era válida até a época prevista para extinção do regime (final de 1999). 
uma reclamação de não-violação do tipo descrito no Artigo XXIII: l(b) do GATT, que dispõe sobre possível anulação ou prejuízo de benefícios auferidos pelo país.

Os Estados Unidos, aparentemente, não sentiram suficiente segurança com os termos do pedido elaborado pelo Japão. Em 9/8/96, um dia após ter solicitado sua participação conjunta na consulta, solicita uma outra (WT/ DS52/1). Poucas diferenças podem ser observadas entre os dois pedidos. A nova solicitação norte-americana especificava que os requisitos do regime brasileiro (citados no pedido anterior, mas de forma diferente ${ }^{6}$ e acrescentando que novos critérios poderiam ser impostos pelo Ministério do Comércio) expressavam condições para obtenção de benefício em forma de redução da taxa alfandegária. Entre os artigos que estariam sendo particularmente violados, dois dos citados no pedido japonês ficaram excluídos: o XI: 1 do GATT/94 (cujo conteúdo está incluído no citado Artigo 2 do Acordo TRIMs) e o Artigo 27:2 do SMC (pois o que se questiona é a obediência às disposições - contidas no Artigo 27:4 - exigidas para sua aplicação). A precaução norte-americana serviu de exemplo para os demais membros interessados. Nos dias posteriores ao da solicitação dos Estados Unidos, Canadá, Japão, Coréia do Sul e União Européia apresentam pedidos de participação na consulta.

Cabe ressaltar, no momento, alguns pontos da formulação desses pedidos de consulta que exemplificam, por meio do caso que aqui está sendo estudado, aspectos dos acordos atingidos na Rodada Uruguai que foram discutidos anteriormente (ver HOLLANDA, 2003).

As medidas proibidas pelo Artigo 2 do Acordo TRIMs, detalhadas no Anexo do acordo, nada mais fazem do que repetir proibições contidas em dois artigos do GATT/94, ambos também citados na primeira solicitação (e somente um na segunda). Isto parece constituir uma evidência de que o Acordo

6 Enquanto a solicitação do Japão fazia referência aos requisitos de conteúdo nacional e de compensação comercial, o dos Estados Unidos citava os requisitos de conteúdo médio doméstico, compensação comercial e conteúdo local referentes aos insumos. O primeiro e o terceiro requisito citado neste pedido referem-se, aparentemente, ao único "índice médio de nacionalização" - que consta do Decreto 1761 e se aplica tanto às montadoras como aos produtores de insumo (matériaprima e autopeças). 
TRIMs atingido na Rodada Uruguai cumpre uma missão prática: a de tornar claro que medidas outrora proibidas como regra geral - eventualmente admitidas como exceção para os países em desenvolvimento pelo conteúdo do Artigo XVIII:B -, mas amplamente utilizadas pelos signatários do antigo GATT, passariam a ser praticamente coibidas a partir da criação da OMC; ou, alternativamente, a permissão para seu uso exigiria uma compensação para empresas dos países que apresentam a queixa.

Os artigos do Acordo SMC citados nas solicitações de consulta referem-se a subsídios vinculados ao desempenho exportador, medida não atingida pelas disposições do Acordo TRIMs. ${ }^{7}$ A referência pode ser entendida como uma forma de os países queixosos desejarem já deixar claro que os subsídios (em forma de reduções do imposto de importação) vinculados ao desempenho exportador oferecidos pelo regime brasileiro não se enquadrariam nas exceções abertas para países em desenvolvimento, por não satisfazerem os dispositivos do Artigo 27:4.

As partes envolvidas nessas consultas de agosto de 1996 não chegaram a um acordo para solução do conflito. ${ }^{8} \mathrm{O}$ regime automotivo foi o alvo principal das críticas levantadas ao longo do exame das políticas comerciais do Brasil nas reuniões do Órgão de Revisão de Políticas Comercias da OMC, em outubro de 1996. (WTO, 1996a).

\section{AS COTAS TARIFÁRIAS}

Numa clara intenção de contornar a oposição externa a seu regime automobilístico, o governo brasileiro assina o Decreto 1987 em 20/8/96, que estabelece um sistema de cota tarifária, com validade prevista de um ano.

7 Numa interpretação liberal, LOW \& SUBRAMANIAN (1996) consideram a não proibição do requisito de desempenho exportador como a principal deficiência do Acordo TRIMs.

8 Isso ficou evidenciado em declarações de representantes dos membros que apresentaram o pedido de consultas na OMC que foram publicadas na imprensa nacional. (Ver e. g. Folha de S. Paulo, 16/8/96 e 10/9/96; O Estado de S. Paulo, 21/8/96, 27/8/96 e 10/9/96; Gazeta Mercantil, 9/9/96). Também já ficava expressa a discordância formal desses representantes em relação ao sistema de cotas tarifárias introduzido "por iniciativa unilateral do Brasil". 
A medida fora informalmente apresentada pela representação brasileira na OMC em julho, o que não evitou a formalização de pedidos de consulta. De acordo com as disposições do novo decreto, as montadoras que não haviam aderido ao regime poderiam importar, ao longo dos doze meses seguintes, um total de 50 mil veículos com uma alíquota correspondente a $50 \%$ da tarifa cheia; ou seja, até agosto de 1997, essas montadoras poderiam importar, em conjunto, 50 mil veículos, pagando um imposto de $35 \%$, equivalente à alíquota paga (até o final de 1996) pelas montadoras que aderiram ao regime, inclusive por aquelas ainda não instaladas, mas que já haviam formalizado pedido de entrada (casos da Renault e Chrysler). O decreto ainda estabelecia que, se um país entrasse com pedido de panel, a redução da alíquota seria suspensa.

A cota de 50 mil veículos seria inicialmente dividida entre Japão (47,5\%), Coréia do Sul $(33,1 \%)$ e União Européia $(19,4 \%)$, com base na média de exportações de carros pelas montadoras que não aderiram ao regime durante os três anos anteriores ao registro da medida na OMC. Nos anos seguintes ocorreriam renovaçóes do sistema de cotas, com modificação da parcela de cada membro à medida que novas empresas oficializassem a intenção de entrada no País e aderissem ao regime. Assim, a renovação anual que se tornaria válida em setembro de 1997 introduziu uma diminuição nas parcelas do Japão e da Coréia do Sul, em benefício da União Européia, devido à adesão da Honda e da Asia Motors ao regime brasileiro. A cota total de importações beneficiadas ficou mantida em 50 mil automóveis nas renovações de 1997 e 1998, com uma alíquota correspondente a 50\% da tarifa cheia. Em setembro de 1999, o sistema de cotas tarifárias é prorrogado até o final do ano, de forma a coincidir seu término com o prazo de encerramento do regime automotivo. Dava-se, então, oportunidade para completar a cota do período anterior que não havia sido plenamente aproveitada. Com a retração do mercado - que se tornou mais forte, no caso dos importados, com a desvalorização do real no início de 1999 -, do total dos 50 mil carros importados que poderiam se beneficiar da redução da alíquota entre setembro de 1998 e agosto de 1999 tinha ocorrido, até o final de junho, apenas um aproveitamento de 20,5 mil unidades. (Gazeta Mercantil, 1/9/99). Para esse último período de vigência das cotas tarifárias as parcelas de cada membro 
eram: Japão 44,1\% (sua maior montadora, a Toyota, não aderiu ao regime), Coréia do Sul 28,9\% e União Européia 27,0\%.

O sistema de cotas tarifárias não trouxe uma solução imediata para o regime automotivo brasileiro na OMC, mas serviu para amolecer a posição dos que contestavam o regime. Formalmente, essa contestação era apresentada como uma questão de princípios - violação às regras da OMC. Mas, na prática, ela foi suavizada pelo escasso prejuízo para as empresas dos principais membros produtores. Aquelas com subsidiárias no Brasil poderiam beneficiar-se diretamente das medidas do regime. Para as demais, o sistema de cotas tarifárias anulava quase toda restrição à importação, diante de uma nova conjuntura na qual a procura por importados já havia se arrefecido. Declaraçôes contrárias ao regime continuaram sendo feitas; mas ao invés de pedido de instalação de um panel, aconteciam solicitações para prorrogação do período de consulta.

Se a posição oficial dos representantes dos principais membros produtores na OMC era contrária a certas medidas do regime automotivo brasileiro, os dirigentes das subsidiárias das montadoras que operavam no País posicionavam-se a favor das regras originais do regime. Essa posição era manifestada notadamente nas declarações dos dirigentes da ANFAVEA. A implantação do sistema de cotas já não fora bem aceito entre esses dirigentes. No início de 1997, quando apareceram as primeiras especulações sobre sua renovação, o presidente do sindicato patronal reagia com o anúncio de possível revisão dos planos de investimentos das montadoras, pois estes haviam sido elaborados sob as regras originais do regime (ver Folha de S. Paulo, 22/2/97). Por outro lado, os dirigentes das subsidiárias deviam estar cientes da necessidade do governo brasileiro oferecer alguma compensação para procurar evitar o estabelecimento de um panel que contestasse o regime que lhes proporcionava consideráveis benefícios. O sistema de cotas acaba sendo renovado sem nenhuma reação oficial por parte das montadoras estabelecidas. 


\section{ESTABELECIMENTO DE INCENTIVOS REGIONAIS}

Em busca de apoio político de congressistas representantes das regióes menos desenvolvidas do País, o governo federal, por meio da MP 1532 de 18/12/ 96, implanta um regime especial de desenvolvimento regional que fornecia benefícios bem mais amplos do que aqueles contidos no regime nacional. Os incentivos fiscais atingem um maior número de impostos, beneficiam montadoras de mais um tipo de veículo (motocicletas) e produtores de suas autopeças, e alguns dos incentivos estavam previstos para durar até 2010, para quando ficou fixado o fim do regime regional. As empresas que se estabelecessem nas regiões Norte, Nordeste e Centro-Oeste do País eram o alvo da MP. O prazo final para aderência ao novo regime por montadoras, inicialmente previsto para o final de março de 1997, seria estendido para o final de maio por ocasião da aprovação da MP, pelo Congresso Nacional, que passa então a ser regulamentada pela Lei 9440 de 13/3/97. Na redação da lei, o prazo final para as fornecedoras é prorrogado para março do ano seguinte.

Como seria de se esperar, a primeira manifestação externa contra o novo regime parte da Argentina. Essa oposição seria posteriormente abrandada por concessões no comércio bilateral de outros produtos. O governo brasileiro certamente também previa novos problemas no âmbito da OMC (onde a MP foi notificada ao Comitê SMC), pois, para adesão ao regime especial, foram estipuladas condições que incluíam requisitos de compensação comercial e índice de nacionalização (de $50 \%$ até 2001 e de $60 \%$ a partir de 2002). Essas medidas contrariam provisões dos Acordos TRIMs e SMC, mas, aparentemente, um problema adicional na esfera da OMC foi considerado menos relevante do que o apoio, no Congresso, para uma questão de política interna: a emenda sobre a reeleição do Presidente da República.

Entre as 25 montadoras de diferentes tipos de veículos que aderiram ao regime regional no prazo citado (até maio de 1997), a coreana Asia Motors, controlada pela Kia, com projeto para ser desenvolvido em Camaçari, na Bahia, foi a que assumiu compromissos de investimento mais elevados (US\$ 719 milhões). Tendo sido uma das primeiras a aderir ao novo regime, a empresa logo começa a importar veículos com alíquota reduzida pela metade, 
com o compromisso de cumprir o requisito de exportações a partir de 1999, para quando estava previsto o início de sua atividade produtiva no País. (Gazeta Mercantil, 20/1/97). A crise asiática do final de 1997 levaria a Kia à falência e o projeto de sua subsidiária deixa de ser cumprido. A empresa fica, então, sujeita ao pagamento da multa prevista no acordo, por causa dos veículos importados com benefícios fiscais em 1997. A massa falida da empresa seria posteriormente absorvida pela Hyundai, que ainda tentava, no início de 2001, livrar-se das multas e obter os incentivos à custa do contrato que fora assinado pela Kia, para reativar o antigo projeto desta empresa.

O projeto proposto pela Asia Motors seria amplamente superado pelo da Ford que, em 1999, viria transferir seu projeto originalmente destinado ao Rio Grande do Sul para a Bahia, após a retirada do apoio do novo governo do Estado gaúcho. Isto exigiu uma modificação da Lei 9440 (resultante da aprovação pelo Congresso, em 14/3/97, da MP dos incentivos regionais), com o estabelecimento de um novo período (até o final de 1999) para aderência ao regime regional. Os investimentos associados ao projeto da Ford foram estimados em US\$ 1,3 bilhão, e contaria com apoio de empréstimos do Banco Nacional de Desenvolvimento Econômico e Social (BNDES), do Banco do Nordeste e do governo baiano.

\section{NOVAS CONSULTAS}

Se os membros da OMC que apresentaram os pedidos de consulta em agosto de 1996 não consideraram satisfatórias as justificativas fornecidas pelo Brasil, por outro lado, eles não utilizaram o prazo mínimo de sessenta dias para um pedido de estabelecimento de um panel. Isto parece indicar que a oposição ao regime automotivo brasileiro no âmbito da $\mathrm{OMC}$ não era muito forte ou, ao menos, daria margem para troca de concessões. $\mathrm{O}$ fato de os principais membros produtores de automóveis terem montadoras estabelecidas - ou em vias de se estabelecerem (caso do Japão e Coréia do Sul) - no Brasil, sem dúvida diminuiu o ímpeto para o questionamento do regime.

Em 10/1/97, os Estados Unidos solicitam nova consulta bilateral sobre o regime automotivo brasileiro (WT/DS65/1). O pedido realça especifica- 
mente o Decreto 1987, que introduziu as cotas tarifárias, e a MP 1532, que concedeu os incentivos regionais, mas também faz referências a qualquer medida que tenha modificado aquelas que foram objeto da consulta realizada em agosto de 1996, para as quais ainda não se havia obtido uma solução. Os acordos e seus dispositivos que estariam sendo violados são os mesmos invocados no pedido anterior. ${ }^{9}$ Ao contrário do que acontecera em agosto, nenhum outro membro pediria participação conjunta nesta consulta. A delegação brasileira aceita o pedido de consulta, salientando, em sua resposta, que não concordava com as alegadas violações aos acordos assumidos.

As duas medidas realçadas no pedido foram aquelas que introduziram modificações (cotas tarifárias) ou medidas adicionais (incentivos regionais) relevantes na política para o setor. No caso das cotas tarifárias, a medida não afetava diretamente os interesses das montadoras norte-americanas de automóveis, ${ }^{10}$ uma vez que a única montadora não estabelecida no País (Chrysler) já havia anunciado sua aderência ao regime, que viria a se materializar com a fábrica construída no Paraná. ${ }^{11}$ Os incentivos regionais não prejudicavam as montadoras norte-americanas. Ao contrário, os acontecimentos futuros colocariam os interesses norte-americanos como principal beneficiado pelo regime regional. A GM, por meio de uma subsidiária (Brazauto), foi uma das 25 empresas que anunciaram sua adesão ao regime especial em 1997. Mas a grande beneficiada seria a Ford, com sua tardia adesão ao regime.

Os Estados Unidos e o Japão são os membros que mais procuram realçar que suas queixas na OMC estariam subordinadas à questão de princípio (violação aos compromissos assumidos no organismo), e não a seus interesses - embora isto pareça ser contrariado, ao menos no caso norte-ameri-

9 Os acordos e artigos citados são: I: 1 e III:4 do GATT/94; 2 do TRIMs; 3 e 27:4 do SMC, além de anulação ou prejuízos de benefícios na forma descrita pelo XXIII do GATT/94.

10 Por outro lado, ao levar formalmente a questão para a OMC, os Estados Unidos fortificavam sua reivindicação para extensão dos benefícios do sistema de cotas tarifárias às importações de caminhão, de modo a favorecer as exportações de duas montadoras de menor porte (Navistar e Caesa).

11 Essa fábrica, que produzia apenas a picape Dakota, teve curta vida; é fechada em 2001. 
cano, por diversas medidas tomadas por seus dirigentes. Torna-se, então, relevante examinar até que ponto as duas novas medidas traziam conflitos adicionais com os dispositivos dos acordos administrados pela OMC. Cotas tarifárias, em si, não são proibidas pelas regras da $\mathrm{OMC}$, e sua adoção veio suavizar o impacto de medidas que já vinham sendo contestadas - embora isto não se aplique às exportações de automóveis norte-americanas. Mais problemática mostrava-se a medida de incentivos regionais; como estes são considerados subsídios, de acordo com a definição adotada pelo Artigo 1 do Acordo SMC, são principalmente com as provisões desse acordo que a medida deve ser confrontada. Essa questão pode ser examinada pelos próprios termos do pedido de consultas que logo seria apresentado pela delegação da União Européia.

As consultas formais solicitadas pelos Estados Unidos realizaram-se em Genebra entre janeiro e fevereiro de 1997. Da mesma forma que as consultas do ano anterior, elas não levaram a um acordo definitivo e nem a um pedido de estabelecimento de panel.

No início de 1997, a União Européia também anunciava sua intenção de solicitar novas consultas sobre o regime. O pedido é formalizado em 7/5/ 97 (WT/DS81/1). As medidas ressaltadas no pedido eram aquelas mesmas citadas na solicitação norte-americana. As regras do regime geral e aquelas referentes aos incentivos regionais já haviam sido, então, aprovadas em forma de leis pelo Congresso Nacional (Leis 9449 e 9440, de 14/3/97). As medidas contidas nessas leis e no decreto sobre as cotas tarifárias são aquelas ressaltadas na nova solicitação.

Comparando-se essas duas solicitações de consultas, pode-se notar que, além de um tom mais diplomático, ${ }^{12}$ o pedido europeu apresenta observações mais detalhadas, como já acontecera no pedido de participação nas consultas do

12 Enquanto o pedido apresentado pelos Estados Unidos (WTO, 1997a) afirma que as medidas do regime violam as obrigações assumidas pelo Brasil na OMC e anulam ou prejudicam benefícios norte-americanos, a solicitação européia (WTO, 1997b) refere-se à sua "preocupação com aparente falta de conformidade das medidas com as mesmas obrigaçóes, que podem anular ou prejudicar...e podem causar" efeitos adversos... 
ano anterior, e cita um maior número de artigos que poderiam estar sendo violados pelas medidas dos regimes brasileiros. ${ }^{13}$ Seu exame fornece uma previsão sobre os diversos passos que seriam seguidos por seus representantes durante a realização da consulta - especificamente no referente às questões relacionadas às duas leis de março de 1997 em confronto com compromissos assumidos pelo País no Acordo SMC.

Em sua solicitação, a União Européia aponta que os incentivos tarifários e outros benefícios fornecidos para os produtores por meio das duas leis constituem subsídios específicos, conforme definição dos Artigos 1 e 2 do Acordo SMC. Como a obtenção desses subsídios está condicionada aos requisitos de compensação comercial e de conteúdo doméstico, eles preencheriam os critérios que definem os subsídios proibidos no Artigo 3:1. Isto deixaria as medidas dos regimes brasileiros sujeitas às provisões do Artigo 4 (recursos contra subsídios proibidos), não fosse os benefícios permitidos ao País por seu status de nação em desenvolvimento e, conseqüentemente, com a possibilidade de invocar as regras do tratamento especial e diferenciado proporcionado pelo Artigo 27. A esse respeito, dever-se-ia discutir se os subsídios condicionados ao desempenho exportador estariam ou não violando as diversas provisões do parágrafo 4 do referido artigo. Em seguida, o documento observa que, mesmo que a proibição dos subsídios possa ser questionada pela regra de tratamento especial e diferenciado, a União Européia considerava que eles causaram efeitos danosos à sua economia - conforme definição do Artigo 5, o que os enquadraria na classe dos subsídios acionáveis -, por terem provocado redução nas importações de veículos europeus pelo mercado brasileiro, deslocamento nas exportações de veículos europeus para terceiros e efeitos adversos sobre preços e volume de vendas de veículos europeus no mercado brasileiro. Por último, o documento aponta o desacordo entre os prazos concedidos pelo regime regional brasileiro, que

13 Além dos artigos citados na solicitação norte-americana, são acrescentados os Artigos X (publicação e administração dos regulamentos do comércio) e XIII (administração não-discriminatória de restrições quantitativas) do GATT/94, e o Artigo 5 (efeitos danosos de subsídios acionáveis) do Acordo SMC. 
vão até 2010 , e aqueles previstos pelo Artigo 27 (5 anos para o requisito de conteúdo local e 8 para o de desempenho exportador - este prorrogável apenas após consulta e autorização do Comitê de Subsídios).

As consultas formais entre os representantes do Brasil e da União Européia ocorreram em Genebra no mês de junho de 1997. O anúncio, na mesma época, da renovação do sistema de cotas tarifárias, com aumento da parcela das importações provenientes da União Européia, pode ter sido proposital. Assim como no caso das consultas bilaterais com os Estados Unidos, as reuniões não levaram a um acordo definitivo, mas, como indicariam ocorrências posteriores, diminuíram a ameaça de pedido para estabelecimento de um panel.

\section{AS CONSULTAS PENDENTES}

Como visto nas seções precedentes, as quatro reuniões de consultas formais sobre o regime brasileiro realizadas em Genebra não levaram a um acordo. Ao mesmo tempo, as partes reclamantes não solicitaram o estabelecimento de um panel. No caso do pedido formalizado pelos Estados Unidos no início de 1997, a consulta bilateral de Genebra foi logo seguida por outras reunióes, a primeira das quais realizada em Belo Horizonte em maio do mesmo ano. Esta também não levou a um acordo. Novas reuniões entre representantes dos dois governos foram feitas em outubro, por ocasião da visita do Presidente Clinton ao Brasil. Outras aconteceram até março de 1998, quando um acordo é firmado entre os dois países. Da parte do Brasil, houve algumas concessões, como uma pequena ampliação das importações que poderiam ser realizadas com incentivo tarifário para cada dólar exportado por uma empresa. Por outro lado, o Brasil obteve a permissão de poder cobrar das newcomers, depois do encerramento do regime nacional no final de 1999 , os compromissos assumidos na época de adesão. Como foi visto, o regime dava a essas empresas o direito de compensar suas importações beneficiadas pelo incentivo tarifário por exportações que se realizassem nos três anos seguintes. A formulação do acordo também envolveu a interpretação de que ficaria eliminada a ameaça de um pedido para estabelecimento de um panel por parte da nação norte-americana (ver Folha de S. Paulo, 1/3/98 e 
$5 / 3 / 98$ ). De fato, essa ameaça foi atenuada, mas, potencialmente, não chegou a ser eliminada.

Nos casos relacionados com Japão, Coréia do Sul e União Européia, a cada renovação do sistema de cotas tarifárias concedida pelo governo brasileiro, deixava-se explícito que o benefício poderia ser suspenso "se assim recomendar o interesse nacional." (Folha de S. Paulo, 4/10/99). Por ocasião da reabertura do prazo para adesão aos incentivos regionais, em junho de 1999, para atender aos interesses da Ford e do governo baiano, a ameaça de um pedido de panel por parte daqueles três membros tornou-se mais presente, conforme acentuaria o ministro Lafer. (Folha de S. Paulo, 18/7/99). E essa ameaça seria mais uma vez atenuada com a prorrogação do sistema de cotas tarifárias até o final do ano, quando era tido como certa sua finalização em setembro. (Gazeta Mercantil, 18/6/99). A razão dessa prorrogação era mais uma vez explicada - como salientou o Embaixador Graça Lima, condutor das negociações na esfera do Ministério das Relações Exteriores - pelo objetivo de dar, ao governo brasileiro, uma arma de pressão contra eventual pedido de panel por parte daqueles membros. (Gazeta Mercantil, 1/9/99 e Folha de S. Paulo, 4/9/99).

Os resultados de um panel, além de incertos, poderiam trazer benefícios comerciais para os países reclamantes somente após um período superior a um ano, enquanto o sistema de cotas tarifárias trazia benefícios imediatos para empresas daqueles países. A relevância da defesa de um princípio - obediência aos compromissos assumidos na OMC - nunca parece ter suplantado, na prática, a defesa dos interesses comerciais de cada membro naquela instituição. $\mathrm{O}$ fato de a ameaça de um panel não ter sido eliminada, mesmo por parte de um pedido dos Estados Unidos após o acordo de 1998, pode ser deduzido pelo uso de um artifício utilizado pelos representantes dos membros que haviam solicitado as consultas. No quadro das disputas ainda não solucionadas neste organismo, as quatro consultas sobre o regime brasileiro ainda estão classificadas, em novembro de 2003 (WT/DS/OV/17), como "pendentes", o que é uma forma dos membros queixosos deixarem explícito que a questão ainda não fora resolvida. Mantém-se, com esse artifício, uma pressão sobre o país-alvo da queixa, mesmo que seja para obter concessões em outras esferas das relações de comércio internacional. 
Não se deve pensar que tenha ocorrido algo de original no uso do artifício para o caso do regime automotivo brasileiro. $\mathrm{O}$ mesmo artifício já era bastante usado na época do GATT. No sumário apresentado pelo Secretariado da OMC em julho de 2001 constavam 92 casos de pedidos para assuntos distintos (considerando-se, por exemplo, os quatro pedidos sobre o regime brasileiro como um caso) classificados como "consultas pendentes". Entre estes, 66 haviam sido solicitados há mais de um ano. O caso do regime automotivo brasileiro era o quinto mais antigo. (WTO, 2001a). São casos tidos como ainda não resolvidos, pois a instituição não recebera notificação sobre sua solução.

\section{O FIM DO REGIME AUTOMOTIVO BRASILEIRO E O CA- MINHO PARA O REGIME COMUM DO MERCOSUL}

O encerramento oficial do regime automotivo brasileiro ocorreu, como previsto, no final de 1999. Mas, ao contrário do que estava antes previsto, ele não foi então substituído por um regime comum para o Mercosul, com pleno livre comércio entre seus membros.

$\mathrm{Na}$ reunião de acompanhamento das políticas comerciais brasileiras no Órgão de Revisão de Políticas Comerciais da OMC, em outubro de 2000, os esclarecimentos fornecidos pelo representante brasileiro foram relativamente bem aceitos, ao contrário do que acontecera na reunião de 1996. Em sua avaliação final, o chairperson do Órgão observava:

"Its special automotive regime having given rise to concerns earlier, the Brazilian delegation emphasized that all benefits to that industry had ceased at the end of 1999." (WTO, 2000).

A referência do Secretariado do Órgão sobre o mesmo tópico havia sido um pouco menos incisiva do que a da delegação brasileira:

"The Brazilian antomotive regime was largely phased-out as schedulled in December 1999.” (WTO, 2000; grifo meu) 
A não total eliminação das prescrições do regime deve-se a elementos já discutidos neste trabalho. De um lado, as obrigações assumidas pelos newcomers que aderiram ao regime geral a partir de 1997 deveriam ser cumpridas ao longo de um período de três anos, estendendo, portanto, para além do final de 1999. Isto, como foi visto, ficou aceito no acordo concluído com os Estados Unidos em 1998. Mas o que deve ser considerado mais problemático são as prescrições do acordo de incentivo regional, que inclui subsídios que se estendem até 2010 , associados à compensação comercial e ao cumprimento do índice de conteúdo local. Esse problema não era ignorado pelo corpo diplomático brasileiro; uma das reivindicações prioritárias da delegação brasileira para a Reunião de Seattle era a de estender, para os países em desenvolvimento, o prazo para a vigência de subsídios associados ao desenvolvimento regional. (Folha de S. Paulo, 24/10/99). Possivelmente em virtude dessas restrições, as quatro solicitações de consultas formais ainda estivessem classificadas como pendentes; existiam elementos ativos do regime geral e do regime especial para o desenvolvimento regional, mas não existiam mais incentivos à entrada de novas firmas e nem privilégios para importação de veículos pelas montadoras estabelecidas, pois a redução de $50 \%$ do imposto de importação até 2010 no regime regional refere-se apenas às compras de máquinas, equipamentos e matérias-primas. Fora as importações de veículos incentivadas por acordos regionais específicos (Mercosul e México), as demais estão subordinadas à alíquota de $35 \%$, que corresponde à tarifa consolidada na OMC.

Quanto ao regime comum para o Mercosul, um acordo firmado em 1998 adiava sua adoção para 2004. Um novo acordo seria assinado em junho de 2000 entre Brasil e Argentina; com algumas modificações, sua versão final é aprovada em dezembro. O regime comum, com a queda de todas barreiras intra-regionais ao livre comércio, fica então fixado para entrar em vigor no início de 2006.

Para o período de transição (até o final de 2005) é estabelecida uma série de regras que entram em vigor em março de 2001. Uruguai e Paraguai aderem ao acordo nos meses seguintes, com adaptações de algumas regras. Para Brasil e Argentina, a Tarifa Externa Comum (TEC) ficou mantida em 
$35 \%$. O fluxo isento de tarifas no comércio de veículos e autopeças entre os dois parceiros seria administrado com crescente flexibilidade, tendo-se como referência o equilíbrio trimestral (medido de forma agregada e em dólar) na balança do setor. $\mathrm{O}$ valor das importações que excedessem o limite seria taxado em $70 \%$ da TEC. A crise econômica da Argentina provoca forte queda em suas importações do setor automotivo. Com isso, o valor de suas exportações para o Brasil supera os limites de isenção fixados para 2001 (US\$ 1 de importação para US\$ 1,06 de exportação) e 2002 (US\$ 1 para US\$ 1,15). Um novo acordo assinado em setembro de 2002 anula a multa para a exportação excedente de 2001 e amplia a regra de flexibilidade para os quatro últimos anos do período de transição.

O acordo estabeleceu, para o período de transição, um índice de conteúdo regional de $60 \%$ para veículos. A Argentina fixa ainda um índice de conteúdo nacional de $30 \%$ para automóveis produzidos no país. As autoridades econômicas dos dois países não previam qualquer problema na OMC quanto à aceitação da regra de conteúdo regional. ${ }^{14}$ Quanto à compatibilidade do índice de conteúdo nacional argentino com o Acordo TRIMs, a questão permaneceu pendente até meados de 2001. Argentina, e mais sete países que notificaram TRIMs em 1995, haviam levado para Seattle um pedido de prorrogação do período de transição (que terminaria no final de 1999) para eliminação das medidas, com base no dispositivo do Artigo 5:3 do acordo. Com o fracasso da reunião, a questão foi transferida para Genebra, para ser

14 O Artigo XXIV do GATT/94, bem como o "entendimento" sobre sua interpretação assinado em Marrakesh, não fazem qualquer referência a tal TRIM regional. Isso não destoa da falta de precisão que caracteriza as regras do artigo. É também reconhecido que a OMC não tem se mostrado forte para enfrentar medidas tomadas por uniões alfandegárias e áreas de livre comércio que se mostram incoerentes com os princípios multilaterais de livre comércio. No caso do Mercosul, o problema se mostra ainda mais nebuloso porque o acordo sobre sua criação foi notificado também sob a Cláusula de Habilitação, cujas regras, que refletem o princípio de tratamento especial e diferenciado, também estão mal definidas. Os dois comitês da OMC que examinavam o acordo ainda não haviam concluído o estudo (ver, sobre o assunto, THORSTENSEN, 1999, p. 221237). A freqüente preocupação manifestada por dirigentes da $\mathrm{OMC}$ com relação à proliferação de acordos regionais de livre comércio e as recentes reivindicações de representantes de países como Brasil e Índia no sentido de uma definição mais precisa das regras de tratamento especial e diferenciado fornecem indícios de que as duas questões continuam inconclusas. Na Reunião Ministerial de Doha ficou acertada uma revisão de todas as provisões de tratamento especial e diferenciado dos acordos da OMC, de forma a torná-las mais precisas, efetivas e operacionais. 
examinada pelo Conselho sobre Comércio de Bens. Em decisão tomada em novembro de 2001 (G/L/497), o Conselho atende o pedido argentino e amplia para até o final de 2003 o período de transição para eliminação dos TRIMs. Por sua vez, no acordo para o setor automotivo assinado com o Brasil em setembro de 2002, a Argentina compromete-se a uma redução escalonada de seu índice de conteúdo nacional até sua eliminação em janeiro de 2006.

\section{NOTAS FINAIS}

Os acordos assinados no final da Rodada Uruguai impuseram maiores limites aos graus de liberdade do governo de uma nação para elaboração de políticas industriais. Medidas antes amplamente aceitas como parte de uma política de desenvolvimento - inclusive consideradas como elementos necessários em tal política - passaram a ser tratadas como prejudiciais aos interesses das próprias nações que as adotavam. No entanto, o exame do caso da política para o setor automotivo brasileiro na segunda metade da década de noventa e de sua interação com as disputas na OMC evidencia certa acomodação ante os princípios do livre comércio e, mais especificamente, diante das regras dos acordos assinados em Marrakesh. Diversas medidas da política setorial foram levadas ao organismo internacional, mas seu questionamento não passou da fase de consultas. Estas consultas tornaram-se "pendentes" na nova instituição, enquanto medidas adicionais eram adotadas para adequar o regime a certas compensações - como as cotas tarifárias - para eliminar, ou diminuir, o "dano" causado às empresas que não aderiram ao regime. $\mathrm{Ou}$ seja, a "pendência" exerce a função de manter certa pressão sobre a política setorial e de propiciar, em troca, alguma compensação comercial para os membros que apresentaram a solicitação de consultas. Em conclusão, os limites impostos pelas regras dos acordos assinados em Marrakesh foram substancialmente contornados, de maneira que o contraste entre as políticas para o setor, antes e depois da criação da OMC, ficou atenuado.

Essa acomodação só foi possível por serem estrangeiras as empresas montadoras que se beneficiavam das primeiras medidas do regime, assim como 
aquelas que tiveram afetados seus interesses exportadores. Havia espaço para uma medida de compensação (cotas tarifárias). Um contraste pode ser feito com o caso da disputa com o Canadá no setor aeronáutico. Neste, acontece uma disputa que envolve interesses exportadores de empresas nacionais dos dois países para terceiros. Há pouco espaço para compensação ou conciliação de interesses. Tornou-se, então, mais forte a percepção dos efeitos da atuação da nova instituição mundial.

O exame das interações entre as medidas da política setorial analisada e o desdobramento das controvérsias sobre elas na OMC ilustra um ponto que já fora observado em relação ao antigo GATT por representante do Canadá: a instituição tornara-se antes um foro de políticas de comércio do que um órgão em defesa de princípios do livre comércio (ver OSTRY, 1997, p. 99).

\section{REFERÊNCIAS BIBLIOGRÁFICAS}

BRASIL, D.O.U. de 31/12/94. Resultados da Rodada Uruguai do GATT. São Paulo: Aduaneiras, 1995.

GATT. The Uruguay Round Final Act: full texts. April 1994 (site da WTO).

HOLLANDA Filho, Sergio B. Os desafios da indiistria antomobilística: a crise da modernização. São Paulo: IPE-USP, 1996.

. Nota: o estabelecimento de um regime automotivo diante da criação da OMC. Estudos Econômicos, v. 33, n. 4, p. 771-792, out./dez. 2003.

LAFER, Celso. A OMC e a regulamentação do comércio internacional: uma visão brasileira. Porto Alegre: Livraria do Advogado, 1998.

LOW, Patrick; SUBRAMANIAN, Arvind. Beyond TRIMs: a case for multilateral action on investment rules and competition policy? In: MARTIN, W.; WINTERS, L. A. (eds.), The Uruguay Round and the developing countries. Cambridge, U.K.: Cambridge University Press, 1996.

OSTRY, Sylvia. The post-cold war trading system: who's on first? Chicago: The University of Chicago Press, 1997.

THORSTENSEN, Vera. OMC - Organização Mundial do Comércio: as regras do comércio internacional e a rodada do milênio. São Paulo: Aduaneiras, 1999. 
WTO. Brazil - Trade policy review. Site da WTO, 1996 a.

. Brazil - Certain automotive investment measures. WT/DS51/1 a WT/DS51/7. Site da WTO, 1996 b.

. Brazil - Certain measures affecting trade and investment in the automotive sector. WT/DS52/1 a WT/DS52/6. Site da WTO, 1996c.

. Brazil - Certain measures affecting trade and investment in the automotive sector. WT/DS65/1 e WT/DS65/2. Site da WTO, 1997a.

. Brazil - Measures affecting trade and investment in the automotive sector. WT/DS81/1. Site da WTO, 1997b.

. Brazil - Trade policy review. Site da WTO, 2000.

. Overview of the state-of-play of WTO disputes. (13/07/2001), site da WTO, 200la.

. Market access: unfinished business - Post-Uruguay Round inventory and issues. Special Study n. 6, site da WTO, 2001b.

. Moore hails implementation breakthrough. Press Release/239, site da WTO, 2001c.

Este artigo foi extraído de uma pesquisa que contou com apoio de uma bolsa de produtividade do CNPq. O autor agradece a Celso Lafer, pelos esclarecimentos fornecidos na etapa inicial da pesquisa, e a Ana Maria A. F. Bianchi, pelas sugestóes oferecidas. As interpretações aqui apresentadas, bem como todos os erros remanescentes, são de minha exclusiva responsabilidade.

(Recebido em janeiro de 2002. Aceito para publicação em agosto de 2003). 